\title{
Efficacy of Resveratrol and Ursolic Acid on Biofilm Inhibition and Antimicrobial Resistance of Streptococcus uberis
}

\author{
A.J. Greeshma, R.N. Ramani Pushpa, K. Lakshmi Kavitha, T. Srinivasa Rao ${ }^{1}$
}

10.18805/IJAR.B-4697

\begin{abstract}
Background: Bovine mastitis is a multifactorial and is one of the most challenging disease. It can be caused by many different bacterial species, the most common of which are Staphylococcus species and Streptococcus species. The prevalence of different species varies temporally, geographically and also due to control measures adopted in herds. The present study is on the biofilm forming Streptococcus uberis causing mastitis and the effect of antibiofilm agents on the antimicrobial resistance of the microorganisms. Methods: The isolates were identified by Polymerase chain reaction (PCR). Two antibiofilm agents, resveratrol and ursolic acid (UA) each at two concentrations $(30 \mu \mathrm{g} / \mathrm{ml}, 100 \mu \mathrm{g} / \mathrm{ml})$ were used for the study. Biofilm formation and rate of biofilm inhibition was detected using quantitative microtiter plate (MTP) assay and biofilm gene (lux S) was detected using PCR. The isolates treated with antibiofilm agents were subjected to standard disc diffusion test with 7 antibiotics and the change in antibiotic resistance was studied.

Result: The mean \pm SE values of inhibition rates of $29 \mathrm{~S}$. uberis isolates by $30 \mu \mathrm{g} / \mathrm{ml} \mathrm{UA,} 100 \mu \mathrm{g} / \mathrm{ml} \mathrm{UA,} 30 \mu \mathrm{g} / \mathrm{ml}$ resveratrol, $100 \mu \mathrm{g} /$ $\mathrm{ml}$ resveratrol were $33.96 \pm 3.17 \%, 57.40 \pm 2.8 \%, 31.35 \pm 3.12 \%$ and $46.28 \pm 3.47 \%$, respectively. Biofilm inhibiting agents along with all antibiotics had reduced antimicrobial resistance by $1.5-2$ times on in vitro antibiotic resistance testing by disc diffusion at $100 \mu \mathrm{g} / \mathrm{ml}$ concentration. The antibiofilm agents were found to be very effective to control antibiotic resistance of $S$. uberis from mastitic milk samples in vitro.
\end{abstract}

Key words: Antibiotic resistance, Biofilm detection, Biofilm inhibition, luxS gene, Resveratrol, Streptococcus uberis, Ursolic acid.

\section{INTRODUCTION}

Mastitis is an important disease affecting diary animals causing a huge economical loss. Mastitis also has got huge public health significance rather than its economic importance (Sudhan et al., 2005). There are many bacterial, viral and other infectious agents causing mastitis. The most common etiological agent is Staphylococcus aureus followed by Streptococcus species causing about $15 \%$ of mastitis in different parts of India. S. uberis, a primary environmental pathogen is a major cause of mastitis in Dairy cattle. Chronic subclinical mastitis caused by $S$. uberis was extremely costly and difficult to treat (Steeneveld et al., 2007).

Intramammary infections caused by $S$. uberis can vary from subclinical to clinical mastitis and it is about $11.86 \%$ in Finland (Koivula et al., 2007). This is also found to be most common cause of clinical mastitis in the UK (23.5\%) (Bradley et al., 2007). S. uberis is found to be more often present in chronic infections than in new subclinical cases (Persson et al., 2011).

Biofilm formation has a key role in antibiotic resistance of the microbes. S. uberis forms biofilms in vitro on abiotic surface and the substrates did not appear to have an effect on its ability to form biofilms under the conditions (tryptic soy broth, $5 \%$ sucrose, $5 \%$ lactose) and assays used. Also, S. uberis has the ability of to attach to host cell surface through the $S$. uberis adhesion molecule (SUAM) (Moore, 2009). Traditional antibiotic therapy acts by destructing planktonic cells only, leaving the attached forms to propagate within the biofilm and continue to disseminate when treatment is stopped (Wang et al., 2009). There is evidence
Department Veterinary Microbiology, NTR College of Veterinary Sciences, Gannavaram-521 102, Andhra Pradesh, India.

${ }^{1}$ Department Veterinary Public Health, NTR College of Veterinary Sciences, Gannavaram-521 102, Andhra Pradesh, India.

Corresponding Author: A.J. Greeshma, Department Veterinary Microbiology, NTR College of Veterinary Sciences, Gannavaram521 102, Andhra Pradesh, India.

Email: annjosephgreeshma@gmail.com

How to cite this article: Greeshma, A.J., Ramani Pushpa, R.N, Lakshmi Kavitha, K. and Srinivasa Rao, T. (2022). Efficacy of Resveratrol and Ursolic Acid on Biofilm Inhibition and Antimicrobial Resistance of Streptococcus uberis. Indian Journal of Animal Research. DOI: 10.18805/IJAR.B-4697

Submitted: 29-06-2021 Accepted: 23-12-2021 Online: 11-02-2022

that quorum sensing is important for the construction and/ or dissolution of biofilm communities in some species. So that quorum sensing inhibitors have the potential ability to be used as an adjuvant in antimicrobial therapy (Parsek and Greenberg, 2005).

Resveratrol $\left(3,5,4^{\prime}\right.$-trihydroxystilbene) is a stilbene naturally present in foodstuffs with described antimicrobial activity against several pathogens (Ferreira et al., 2014; Paulo et al., 2010). Resveratrol has got important pharmacology effects, such as anticancer, antioxidation, immunoregulation, anti-inflammation and antibacterial activity (Horiuchi et al., 2007). The ability of resveratrol and its inclusion complex in the inhibition of biofilm formation and in the dispersion of established biofilms as well as its 
Efficacy of Resveratrol and Ursolic Acid on Biofilm Inhibition and Antimicrobial Resistance of Streptococcus uberis

quorum sensing inhibition activity was evaluated. The inclusion complex and resveratrol display a bacteriostatic or bactericidal effect, with this effect being time and concentration dependent and with a faster killing kinetics in the case of resveratrol in comparison to the inclusion complex (Duarte et al., 2015). Ursolic acid (UA) is a relatively nontoxic active ingredient of many medicinal plants and has a broad range of pharmacological effects, including protection against liver injury, antitumor activity, inhibition of mutagenesis in bacteria, anti-inflammation and antiulcer activity (Ren et al., 2005). Zhou et al. (2013) reported the enhancing antimicrobial and anti-biofilm efficacy of UA and xylitol, against $S$. mutans and $S$. sobrinus in the oral environment by synergistic inhibition. The present study is on the effect of antibiofilm agents viz., UA and resveratrol in combination with 7 antibiotics on antibiotic resistance of biofilm forming $S$. uberis isolated from mastitic milk samples of cows and buffalos.

\section{MATERIALS AND METHODS}

\section{Sample collection}

Milk samples were collected with owner's consent as per standard milk collection procedure. Samples were collected aseptically from bovine mastitic cases presented to veterinary hospitals and from farms in and around Krishna, Guntur and west Godavari districts, Andhra Pradesh. The study was conducted in the Department of Veterinary Microbiology, NTR College of Veterinary Sciences, Gannavaram, Andhra Pradesh.

\section{Bacterial isolation and identification}

Approximately $10 \mathrm{ml}$ of milk was collected aseptically from clinical cases into sterile vials. Collected samples from each quarter were transported on ice and immediately cultured or stored at $4^{\circ} \mathrm{C}$ until cultured/enriched. Milk samples were centrifuged at $2000 \mathrm{~g}$ for 10 minutes at $37^{\circ} \mathrm{C}$, supernatant was discarded and $5 \mathrm{ml}$ of brain heart infusion (BHI) broth was added to the sediment and incubated at $37^{\circ} \mathrm{C}$ for $24 \mathrm{hr}$ (Cruickshank et al., 1975). Selective isolation was done by inoculating $0.9 \mathrm{ml}$ of Streptococcus selective (SS) broth with $0.1 \mathrm{ml}$ of culture from the $\mathrm{BHI}$ broth and incubated at $37^{\circ} \mathrm{C}$ in an anaerobic jar for $24 \mathrm{hr}$. The morphology of the organisms was studied by Gram's staining. SS broth with Gram positive cocci in chain were further inoculated on to Edward's medium. The S. uberis isolates were identified phenotypically and genotypically. The cultures showing greyish, pinpointed colonies and/or aesculin hydrolysis on Edward's medium were tentatively identified as Streptococcus species. The suspected isolates of Streptococcus species were further identified by various biochemical tests viz., catalase test, ninhydrin test, sodium hippurate hydrolysis test and type of haemolysis on $7 \%$ sheep blood agar.

\section{DNA extraction}

DNA was extracted by High salt method (Anand Kumar, 2009) and re-suspended in $40 \mu \mathrm{l}$ sterile distilled water and stored at $-20^{\circ} \mathrm{C}$ till use. The procedure followed was,

1. Two $\mathrm{ml}$ of enriched bacterial culture in tryptic soya broth (TSB) was first washed (at 5,000 rpm for 10 minutes) with Phosphate Buffered Saline in fresh Eppendorf tube $(2.0 \mathrm{ml})$ and then washed with TKM-1 solution (Appendix) at 5,000 rpm for 10 minutes.

2. The bacterial cell pellet was suspended in $100 \mu \mathrm{l}$ of TKM2 solution (Appendix) and incubated for $15 \mathrm{~min}$ at $37^{\circ} \mathrm{C}$.

3. Then, $50 \mu$ of $10 \%$ Sodium Dodecyl Sulphate was added and mixed well. Subsequently, $250 \mu \mathrm{l}$ of $6 \mathrm{M}$ Sodium Chloride was added, mixed well and centrifuged at 10,000 rpm for 5 min.

4. The supernatant containing nucleic acid was transferred to fresh microcentrifuge tube $(1.5 \mathrm{ml})$ then 2 volumes of $100 \%$ ethanol were added, mixed thoroughly and centrifuged at $10,000 \mathrm{rpm}$ for $5 \mathrm{~min}$ at $4^{\circ} \mathrm{C}$.

5. The DNA pellet thus obtained was washed twice with $75 \%$ ethanol (at 5,000 rpm for 10 minutes) and finally re-suspended in $40 \mu \mathrm{l}$ sterile distilled water and stored at $-20^{\circ} \mathrm{C}$ till use.

\section{Measurement of DNA concentration and purity}

The concentrations of DNA were measured with Nanodrop $20^{\circ} \mathrm{C}$ (Thermo Scientific, USA) and adjusted to $50 \mathrm{ng} / \mu \mathrm{l}$ for further molecular studies. Pure DNA samples (with an optical density ratio of 1.8 to 2 at $260 / 280 \mathrm{~nm}$ ) were stored at $-20^{\circ} \mathrm{C}$, until further use.

\section{Identification of isolates by PCR}

The nucleotide sequence of primers used for detection of S. uberis (Sub 302/Sub 396) were, F- CGA AGT GGG ACA TAA AGT TA, R- CTG CTA GGG CTA AAG TCA AT (Riffon et al., 2001) coding for 23S rRNA, with specific annealing temperatures of $53^{\circ} \mathrm{C}$. The isolates with luxS gene responsible for biofilm formation in were identified by the specific primer with sequence F- TTT GAT GTT CGC TTG GTT CA, R-AGT TTT GCC CAT TCT TTT GC (Moore, 2009). The time temperature combinations used for PCR are given in Table 1. The PCR amplicons were analysed by electrophoresis on $1.7 \%$ agarose gel stained with 0.5 $\mu \mathrm{g}$ of ethidium bromide $/ 1 \mathrm{ml}$ in Tris-Borate EDTA (TBE) buffer and then visualised by UV gel documentation system (Bio-Rad).

\section{Biofilm detection in S. uberis isolates}

Biofilm forming isolates were identified by MTP assay (Christensen et al., 1985; Merrit et al., 2005) with minor modifications by Moore (2009). Quantification of biofilm/ nonbiofilm producing colonies was done according to Milanov et al. (2015). Cut-off OD is defined as three standard deviations above the mean OD of the negative control. Isolates were classified as follows:

Non-biofilm producers (OD $\leq$ ODc)

Weak biofilm producers (ODc $<$ OD $\leq 2 \times$ ODc)

Moderate biofilm producers $(2 \times$ ODc $<$ OD $\leq 4 \times$ ODc)

Strong biofilm producers (OD $>4 \times$ ODc). 


\section{Biofilm inhibition in biofilm forming $S$. uberis isolates by microtiter plate assay}

Biofilm forming isolates were identified by MTP assay. The antagonist effect of resveratrol and UA on biofilm formation and antibacterial resistance was studied by using different concentrations and by its comparison with the control group that did not receive any treatment. The rate of biofilm inhibition was studied by MTP assay. The $S$. uberis isolates were divided into five groups, group 1- control (isolates without receiving any treatment), group 2- Pure colonies with addition of $30 \mu \mathrm{g} / \mathrm{ml}$ UA, group 3-Pure colonies with addition of $100 \mu \mathrm{g} / \mathrm{ml}$ UA, group 4- Pure colonies with addition of resveratrol at concentration of $30 \mu \mathrm{g} / \mathrm{ml}$, Group 5- Pure colonies with addition of resveratrol at concentration of $100 \mu \mathrm{g} / \mathrm{ml}$.

Biofilm inhibition studies were conducted on the isolates by the following method, with minor modification from Moore (2009). Single colonies of each S. uberis isolate were inoculated into $5 \mathrm{ml}$ of TSB, placed in a shaker incubator at $37^{\circ} \mathrm{C}$ and grown overnight to stationary phase. The following day bacterial cultures were diluted at 1:100 with sterile TSB broth with UA and resveratrol of which final concentrations were $100 \mu \mathrm{g} / \mathrm{ml}$ and $30 \mu \mathrm{g} / \mathrm{ml}$. Hundred $\mu \mathrm{l}$ of the diluted culture were inoculated in a sterile 96 -well $U$ - bottom polystyrene plate (Tarsons, Kolkata) and incubated for 48 hours. Planktonic bacteria were removed by washing the plate four times with $100 \mu \mathrm{l}$ of Phosphate buffered saline and any residual liquid was carefully aspirated. The plate was heat fixed for one hour at $60^{\circ} \mathrm{C}$ and stained with $100 \mu \mathrm{l}$ Hucker's crystal violet solution for two minutes. The excess stain was removed by gentle shaking and washing with water until the water was clear. The plate was blotted dry and 100 $\mu \mathrm{l}$ of a solution containing $10 \%$ methanol and $7.5 \%$ acetic acid was added, the plate was shaken for one minute and placed in plate reader to record the absorbance at $563 \mathrm{~nm}$. The inhibitory rates were calculated using the following formula: Inhibitory rate \% =

$$
\frac{\text { OD563 } \mathrm{nm} \text { of control - OD563 } \mathrm{nm} \text { of sample }}{\text { OD563 } \mathrm{nm} \text { of control }} \times 100 \%
$$

\section{Antibiogram studies}

The modified disc diffusion method of Kirby-Bauer was employed. Antibiotic susceptibility testing was performed using antibiotic test discs (Hi media, Mumbai) and interpretation was done according to 2007 CLSI guidelines. The disc diffusion test was done for each isolate on MuellerHinton agar. Initially antibiogram of isolates without treating with antibiofilm agents was done. For studying the variation in antimicrobial resistance when treated with antibiofilm agents, the $S$. uberis isolates were treated with $30 \mu \mathrm{g} / \mathrm{ml}$ of $\mathrm{UA}, 100 \mu \mathrm{g} / \mathrm{ml}$ of UA, $30 \mu \mathrm{g} / \mathrm{ml}$ of resveratrol and $100 \mu \mathrm{g} / \mathrm{ml}$ of resveratrol for 18 hours and antibiotic sensitivity test was done as per the protocol. The antibiotic impregnated discs and their concentrations used were Penicillin G (10 IU), Tetracycline $(30 \mu \mathrm{g})$, Amoxycillin/Clavulanic acid $(30 / 15 \mu \mathrm{g})$, Streptomycin $(10 \mu \mathrm{g})$, Ceftriaxone $(30 \mu \mathrm{g})$, Erythromycin $(10 \mu \mathrm{g})$ and Enrofloxacin $(10 \mu \mathrm{g})$.

\section{RESULTS AND DISCUSSION \\ PCR detection of S. uberis and luxS gene}

A total of 44 isolates were reacted to species specific $S$. uberis primers with product size of $94 \mathrm{bp}$ (Fig 1). Out of those 29 isolates were biofilm formers and 15 were non biofilm formers. The study was focused on antimicrobial resistance of the biofilm forming isolates. Out of 29 S. uberis isolates tested for the presence of luxS gene $9(31.03 \%)$ isolates reacted to luxS primers with product size of $317 \mathrm{bp}$ (Fig 2). Satish Kumar (2016) also, reported the presence of



Fig 1: PCR amplification product of Sub 302 and Sub 396 oligonucleotide primers for $S$. uberis.

M= Marker; Lane 1= Sample 67; Lane 2= Sample 69; Lane 3= Negative; Lane 4= Negative control; Lane $5=$ Sample 27 ; Lane 6= Sample 72; Lane 7= Sample 76.



Fig 2: $P C R$ amplification product of luxS gene of $S$. uberis. M= Marker; Lane 1= Sample 41; Lane 2= Negative control; Lane $3=$ Negative; Lane $4=$ Negative; Lane $5=$ Sample 71 ; Lane $6=$ Sample 72; Lane 7= Sample 76 . 
lux $S$ gene in $41.6 \%$ of $S$. uberis isolates in agreement with the present findings. In contrary Moore (2009) reported the presence of luxS gene in $96 \%$ of isolates.

\section{Biofilm detection and inhibition studies}

Of the selected 29 isolates on MTP assay 4 were strong biofilm producers, 2 were moderate biofilm producers, 23 were weak biofilm producers (Fig 3). The optical density of the isolates on MTP assay is represented graphically in Fig 4.

Mean \pm SE values of biofilm inhibition rates of UA at concentration of $30 \mu \mathrm{g} / \mathrm{ml}$ and $100 \mu \mathrm{g} / \mathrm{ml}$ was found to be $33.96 \pm 3.17 \%$ and $57.40 \pm 2.8 \%$ respectively. Mean \pm SE values of biofilm inhibition rates of resveratrol at concentration of $30 \mu \mathrm{g} / \mathrm{ml}$ and $100 \mu \mathrm{g} / \mathrm{ml}$ was found to be $31.35 \pm 3.12 \%$ and $46.28 \pm 3.47 \%$ respectively.

\section{Antibiogram of the isolates}

In vitro antibiotic sensitivity test of $S$. uberis revealed that
$79.31 \%$ of the isolates were resistant to Ceftriaxone followed by Erythromycin (41.37\%), Streptomycin (37.93\%), Tetracycline (37.93\%), Penicillin G $(34.48 \%)$, Enrofloxacin (31.03\%), Amoxycillin clavulanic acid $(27.58 \%)$. The results were in agreement with Elango et al. (2010) but the resistance to Ceftriaxone was a contradiction from the study which showed only $7.34 \%$ resistance. In favour of the present study Jain et al. (2012) also reported high sensitivity of Streptococcus isolates to Gentamicin and Ampicillin. Increased antimicrobial resistance rates were identified in Streptococci against enrofloxacin, tetracycline, and erythromycin (Kabelitz et al., 2021). Boireau et al. (2018) found the highest resistance level of $S$. uberis to enrofloxacin with $32.9 \%$. Except for Tetracycline, resistance rates for the antibiotics tested were more or less stable over 10 years, there was a linear increase in resistance to Tetracycline between 2006 and 2016 from $15.7 \%$ to $20.4 \%$.



Fig 3: MTP of S. uberis isolates, G4 to G6- strong; E4 to E6- moderate; C4 to C6- weak; A1 to A3-non biofilm former and A10 to A12negative control.



Fig 4: Graph showing Optical Density of S. uberis isolates on MTP assay. 
The antibiotic resistance of the isolates to selected antibiotics has decreased drastically on treatment with antibiofilm agents. The reduction in antimicrobial resistance was observed highest with UA at $100 \mu \mathrm{g} / \mathrm{ml}$ concentration. The resistance to Ceftriaxone was reduced to $34.48 \%$ and to other antibiotics Erythromycin (27.58\%), Streptomycin (13.79\%), Tetracycline (20.68\%), Penicillin G $(17.24 \%)$, Enrofloxacin (27.58\%), Amoxycillin clavulanic acid (17.24\%). The variation in antimicrobial resistance pattern of $S$. uberis without treating with antibiofilm agents and after treatment with the specified concentrations are in Table 2 and 3 respectively. The variation in antimicrobial resistance of S. uberis is depicted graphically in Fig 5 .

Mastitis is an important disease in diary animals causing huge economic loss mainly due to low production. Recurrent and subclinical infections increase the economic loss. Resistance of microorganism to antibiotics is the major concern of field veterinarians in the treatment of mastitis. Majority are trying a combination antibiotic therapy for good result. In terms of bovine mastitis, besides the invasion of

Table 1: PCR program.

\begin{tabular}{lccccccccc}
\hline \multirow{2}{*}{ Primer/gene } & \multirow{2}{*}{ Product } & \multicolumn{2}{c}{ Initial denaturation } & \multicolumn{2}{c}{ Denaturation } & \multicolumn{2}{c}{ Annealing } & \multicolumn{2}{c}{ Extension } \\
\cline { 3 - 9 } & & Temp & Time & Temp & Time & Temp & Time & Temp & Time \\
\hline Sub (Sub 302 and Sub 396) & $94 \mathrm{bp}$ & $94^{\circ} \mathrm{C}$ & $2 \mathrm{~min}$ & $94^{\circ} \mathrm{C}$ & $30 \mathrm{sec}$ & $53^{\circ} \mathrm{C}$ & $30 \mathrm{sec}$ & $72^{\circ} \mathrm{C}$ & $30 \mathrm{seC}$ \\
S. uberis (luxS) & $317 \mathrm{bp}$ & $95^{\circ} \mathrm{C}$ & $2 \mathrm{~min}$ & $95^{\circ} \mathrm{C}$ & $30 \mathrm{sec}$ & $58^{\circ} \mathrm{C}$ & $1 \mathrm{~min}$ & $72^{\circ} \mathrm{C}$ & $1 \mathrm{~min}$ \\
\hline
\end{tabular}

PCR was run for 35 cycles and final extension step was maintained at $72^{\circ} \mathrm{C}$ for $10 \mathrm{~min}$ for all the oligonucleotide primer sets.

Table 2: Details of antimicrobial resistance pattern of $S$. uberis without treatment and after treating with UA in percentage.

\begin{tabular}{|c|c|c|c|c|c|c|c|c|c|}
\hline \multirow{2}{*}{ Antibiotic disc } & \multicolumn{3}{|c|}{ Group 1} & \multicolumn{3}{|c|}{ Group 2} & \multicolumn{3}{|c|}{ Group 3} \\
\hline & $S$ & 1 & $\mathrm{R}$ & $S$ & I & $\mathrm{R}$ & $S$ & I & $\mathrm{R}$ \\
\hline $\mathrm{P}$ & 13.79 & 51.72 & 34.48 & 17.24 & 58.62 & 24.13 & 41.37 & 41.37 & 17.24 \\
\hline AMC & 72.41 & 0 & 27.58 & 79.31 & 0 & 20.68 & 82.75 & 0 & 17.24 \\
\hline CTR & 17.24 & 3.44 & 79.31 & 24.13 & 10.34 & 65.51 & 51.72 & 13.79 & 34.48 \\
\hline TE & 51.72 & 10.34 & 37.93 & 62.06 & 3.44 & 34.48 & 65.51 & 13.79 & 20.68 \\
\hline$E$ & 20.68 & 37.93 & 41.37 & 34.48 & 37.93 & 27.58 & 65.51 & 13.79 & 20.68 \\
\hline$S$ & 44.82 & 17.24 & 37.93 & 58.62 & 17.24 & 24.13 & 75.86 & 10.34 & 13.79 \\
\hline Ex & 51.72 & 17.24 & 31.03 & 55.17 & 13.79 & 31.03 & 72.41 & 6.89 & 20.68 \\
\hline
\end{tabular}

Table 3: Details of antimicrobial resistance pattern of $S$. uberis without treatment and after treating with resveratrol in percentage.

\begin{tabular}{lccccccccc}
\hline Antibiotic disc & \multicolumn{3}{c}{ Group 1 } & \multicolumn{3}{c}{ Group 4 } & \multicolumn{2}{c}{ Group 5 } \\
\cline { 2 - 9 } & $\mathrm{S}$ & $\mathrm{I}$ & $\mathrm{R}$ & $\mathrm{S}$ & $\mathrm{I}$ & $\mathrm{R}$ & $\mathrm{S}$ & $\mathrm{I}$ \\
\hline P & 13.79 & 51.72 & 34.48 & 17.24 & 55.17 & 27.58 & 37.93 & 37.93 & 24.13 \\
AMC & 72.41 & 0 & 27.58 & 82.75 & 0 & 17.24 & 89.65 & 0 & 10.34 \\
CTR & 17.24 & 3.44 & 79.31 & 20.68 & 10.34 & 68.96 & 34.48 & 10.34 & 55.17 \\
TE & 51.72 & 10.34 & 37.93 & 58.62 & 10.34 & 31.03 & 65.51 & 3.44 & 31.03 \\
E & 20.68 & 37.93 & 41.37 & 34.48 & 27.58 & 37.93 & 51.72 & 17.24 & 31.03 \\
S & 44.82 & 17.24 & 37.93 & 51.72 & 20.68 & 27.58 & 68.96 & 3.44 & 27.58 \\
Ex & 51.72 & 17.24 & 31.03 & 65.51 & 13.79 & 20.68 & 75.86 & 6.89 & 17.24 \\
\hline
\end{tabular}

Antibiotic disc: $P$ - Penicillin G, AMC - Amoxycillin clavulanic acid, CTR - Ceftriaxone, TE - Tetracycline, E - Erythromycin, S - Streptomycin, Ex - Enrofloxacin. S - Sensitive, I - Intermediate, $R$ - Resistant, $n$ - number of isolates.

\section{APPENDIX}

TKM-1 solution

TRIS hydrochloride (Tris $\mathrm{HCl})(\mathrm{pH}-7.6) \quad 10 \mathrm{mM}$

Potassium chloride $(\mathrm{KCl})$

Magnesium chloride $\left(\mathrm{MgCl}_{2}\right)$

Ethylene diamine tetra acetic acid (EDTA) $2 \mathrm{mM}$

TKM-2 solution

TRIS hydrochloride (Tris $\mathrm{HCl})(\mathrm{pH}-7.6) \quad 10 \mathrm{mM}$

Potassium chloride $(\mathrm{KCl}) \quad 10 \mathrm{mM}$

Magnesium chloride $\left(\mathrm{MgCl}_{2}\right) \quad 10 \mathrm{mM}$

Ethylene diamine tetra acetic acid (EDTA) $2 \mathrm{mM}$

Sodium chloride $(\mathrm{NaCl}) \quad 0.4 \mathrm{mM}$ 




Fig 5: The graph showing the increase in the sensitivity to antibiotics using disc diffusion test.

mammary epithelial cells, survival of microorganisms in milk is an important step (Kabelitz et al., 2021). Recurrent infections are mainly due to biofilm formation by microorganism, which is not getting destroyed by the antibiotic therapy. Hygiene conditions, feeding and machine-milking are some of the factors associated with clinical cases caused by S. uberis (Barkema et al., 1999).

The most common phase of the production cycle in which dairy cows acquire an infection with $S$. uberis is dry period. Typically, S. uberis infections are manifested as acute mastitis, during the subsequent lactation (Hughes, 1999). Some infections may eventually turn cow-associated, due to its ability to persist within the mammary tissue. In other cases, the infection is short, but in any case, there is a high risk of re-infection. The risk for the dairy farm lies in the high rate of re-infection even though microbes remain susceptible to most antimicrobial agents (Kromker et al., 2014). Varhimo et al. (2011) described biofilm formation as one of the important virulence factors of some strains of $S$. uberis. Moreover, Crowley et al. (2011) demonstrated that the transition from planktonic to biofilm growth in the S. uberis 0140J strain correlated with an upregulation of several gene products that have been shown to be important for pathogenesis. Biofilm formation plays an important role in persistent and re-infections.

In this study, antibiogram of the isolates before and after treatment with the antibiofilm agents varied positively. The antibiotic resistance of the $S$. uberis isolates to selected antibiotics has decreased drastically on treatment. The increase in concentration of the antibiofilm agent again improved the sensitivity of the isolates to the antibiotics. It suggests that a combination of an antibiofilm agent along with the antibiotics may help to bring the case under control. Jyothi et al. (2018) studied the antagonistic effect of UA on S. aureus biofilms using MTP assay and found $71.5 \%$ and $48.6 \%$ inhibition at UA concentrations of $60 \mu \mathrm{g} / \mathrm{ml}$ and $30 \mu \mathrm{g} / \mathrm{ml}$ respectively, they also showed that the isolates tested to be resistant through antibiotic sensitivity test to commonly used antibiotics were become sensitive to all the tested antibiotics after treatment with UA at both the tested concentrations. The $S$. uberis isolates treated with UA and resveratrol were more sensitive to antibiotics than untreated. Interestingly, for all the antibiotics used the zone of inhibition or no growth was increased after treating with the antibiofilm agents and the increase in sensitivity of the isolates was directly proportional to the concentration of the antibiofilm agent used. Among the studied antibiofilm agents UA at $100 \mu \mathrm{g} /$ $\mathrm{ml}$ was more effective along with antibiotics than resveratrol. Biofilm inhibiting agents along with all antibiotics had reduced antimicrobial resistance by 1.5-2 times on in vitro antibiotic testing by disc diffusion method at $100 \mu \mathrm{g} / \mathrm{ml}$ concentration.

\section{CONCLUSION}

The results from this study gives a ray of hope in the treatment of recurrent clinical mastitis by identifying the biofilm forming pathogens. The use of these antibiofilm agents as intramammary infusions has to be studied in vivo, since the in vitro studies were found to be successful. Anyway, these antibiofilm agents are a hopeful way to tackle the biofilm forming pathogens with existing antimicrobials without any doubt. The extent of increase in sensitivity varies with the combination of antibiotic used and biofilm inhibiting agent selected. UA and resveratrol as an antibiofilm agent, is a promising approach to treat mastitis with the available antibiotics. The studies we conducted are in vitro and which has to be done in vivo also, that will give more clear data for selection of antibiofilm agents, antibiotics and correlation with the cellular factors.

\section{REFERENCES}

Anand Kumar, P. (2009). Evaluation of PCR test for detecting major pathogens of bubaline mastitis directly from mastitic milk samples of buffaloes. Tropical Animal Health and Production. 41(8): 1643-1651. 
Barkema, H.W., Schukken, Y.H., Lam, T.J., Beiboer, M.L. and Benedictus, G. (1999). Management practices associated with the incidence rate of clinical mastitis. Journal of Dairy Science. 82: 1643-1654.

Boireau, C., Cazeau, G., Jarrige, N., Calavas, D., Madec, J.Y., Leblond, A., Haenni, M. and Gay, É. (2018). Antimicrobial resistance in bacteria isolated from mastitis in dairy cattle in France, 2006-2016. Journal of Dairy Science. 101: 9451-9462.

Bradley, A.J., Leach, K.A., Breen, J.E., Green, L.E. and Green, M.J. (2007). Survey of the incidence and aetiology of mastitis on dairy farms in England and Wales. Veterinary Record. 160: 253-257.

Christensen, G.D., Simpson, W.A., Younger, J.J., Baddour, L.M., Barrett, F.F., Melton, D.M. and Beachey, E.H. (1985). Adherence of coagulase-negative Staphylococci to plastic tissue culture plates: A quantitative model for the adherence of Staphylococci to medical devices. Journal of Clinical Microbiology. 22: 996-1006.

Clinical and Laboratory Standards Institute. (2007). Performance Standards for Antimicrobial Susceptibility Testing; Fifteenth Informational Supplement. CLSI document M100-S15. CLSI, Wayne, PA.

Crowley, R.C., Leigh, J.A., Ward, P.N., Lappin-Scott, H.M. and Bowler, L.D. (2011). Differential protein expression in Streptococcus uberis under planktonic and biofilm growth conditions. Applied and Environmental Microbiology. 77: 382-384.

Cruickshank, R., Duguid, J.P., Marmion, B.P. and Swain, R.H.A. (1975). Medical Microbiology $12^{\text {th }}$ edition, Churchhill Livingstone, Edinburgh.

Duarte, A., Alves, A.C., Ferreira, S., Silva, F. and Domingues, F.C. (2015). Resveratrol inclusion complexes: Antibacterial and anti-biofilm activity against Campylobacter spp. and Arcobacter butzleri. Food Research International. 77(2). DOI: 10.1016/j.foodres.2015.05.047.

Elango, A., Doraisamy, K.A., Rajarajan, G. and Kumaresan, G. (2010). Bacteriology of sub clinical mastitis and antibiogram of isolates recovered from cross bred cows. Indian Journal of Animal Research. 44(4): 280-284.

Ferreira, S., Silva, F., Queiroz, J.A., Oleastro, M. and Domingues, F.C. (2014). Resveratrol against Arcobacter butzleri and Arcobacter cryaerophilus: Activity and effect on cellular functions. International Journal of Food Microbiology. 180: 62-68.

Horiuchi, K., Shiota, S. and Hatano, T. (2007). Antimicrobial activity of oleanolic acid from salvia officinalis and related compounds on Vancomycin-Resistant Enterococci (VRE). Biological and Pharmaceutical Bulletin. 30(6): 1147-1149.

Hughes, J. (1999). Bedding systems and mastitis. Proceedings of British Mastitis Conference.

Jain, B., Tewari, A., Bharat., Bhandari, B. and Jhala, M.K. (2012). Antibiotic resistance and virulence genes in Streptococcus agalactiae isolated from cases of bovine subclinical mastitis. Veterinarski Arhiv. 82(5): 423-432.

Jyothi, J.S., Putty, K., Reddy, Y.N., Dhanalakshmi, K. and Umair, M.A.H. (2018). Antagonistic effect of ursolic acid on staphylococcal biofilms. Veterinary World. 11(10): 1440-1444.

Kabelitz, T., Aubry, E., van Vorst, K., Amon, T. and Fulde, M. (2021). The role of Streptococcus spp. in bovine mastitis. Microorganisms. 9: 1497.
Koivula, M., Pitkala, A., Pyorala, S. and Mantysaari, E.A. (2007). Distribution of bacteria and seasonal and regional effects in a new database for mastitis pathogens in Finland. Acta Agriculturae Scandinavica Section A - Animal Science. 57: 89-96.

Kromker, V., Reinecke, F., Paduch, J.H. and Grabowski, N. (2014). Bovine Streptococcus uberis Intramammary Infections and Mastitis. Clinical Microbiology. 3: 157.

Merritt, J.H., Kadouri, D.E. and O-Toole, G.A. (2005). Growing and Analyzing Static Biofilms. Current Protocols in Microbiology. 1-1B: 17.

Milanov, D., Bojana, P., Maja, V., Dalibor, T. and Vladimir. (2015). Investigation of biofilm formation and phylogenetic typing of Escherichia coli strains isolated from milk of cows with mastitis. Acta Veterinaria-Beograd. 65(2): 202-216.

Moore, G.E. (2009). Biofilm Production by Streptococcus uberis Associated with Intramammary Infections. University of Tennessee Honours Thesis projects.

Parsek, M.R. and Greenberg, E.P. (2005). Sociomicrobiology: The connections between quorum sensing and biofilms. Trends in Microbiology. 13(1): 27-32.

Paulo, L., Ferreira, S., Gallardo, E., Queiroz, J.A. and Domingues, F. (2010). Antimicrobial activity and effects of resveratrol on human pathogenic bacteria. World Journal of Microbiology and Biotechnology. 26(8): 1533-1538.

Persson, Y., Nyman, A.K.J. and Gronlund-Andersson, U. (2011). Etiology and antimicrobial susceptibility of udder pathogens from cases of subclinical mastitis in dairy cows in Sweden. Acta Veterinaria Scandinavica. 53-36.

Ren, D., Zuo, R. and Barrios, A.F.G. (2005). Differential gene expression for investigation of Escherichia coli biofilm inhibition by plant extract resveratrol. Applied and Environmental Microbiology. 71(7): 4022-4034.

Riffon, R., Khampoune, S., Hayssam, K., Pascal, D., Marc, D. and Jacqueline, L. (2001). Development of a rapid and sensitive test for identification of major pathogens in bovine mastitis by PCR. Journal of Clinical Microbiology. 39: 2584-2589.

Satish Kumar, D. (2016). Studies on biofilm forming bacterial Pathogens of bovine mastitis. MVSc thesis. Sri Venkateswara Veterinary University, Tirupati.

Steeneveld, W., Swinkels, J. and Hogeveen, H. (2007). Stochastic modelling to assess economic effects of treatment of chronic subclinical mastitis caused by Streptococcus uberis. Journal of Dairy Research. 74(4): 459-467.

Sudhan, N.A., Singh. R., Singh, M. and Soodan, J.S. (2005). Studies on prevalence, etiology and diagnosis of sub clinical mastitis among cross bred cows. Indian Journal Animal Research. 39(2): 127-130.

Varhimo, E., Varmanen, P., Fallarero, A., Skogman, M., Pyorala, S., livanainen, A., Sukura, A., Vuorela, P. and Savijoki, K. (2011). Alpha- and $\beta$-casein components of host milk induce biofilm formation in the mastitis bacterium Streptococcus uberis. Veterinary Microbiology. 149: 381-389.

Wang, X., Yao, X. and Zhu, Z. (2009). Effect of berberine on Staphylococcus epidermidis biofilm formation. International Journal of Antimicrobial Agents. 34(1): 60-66.

Zhou, L., Ding, Y., Chen, W., Zhang, P., Chen, Y. and Lv, X. (2013). The in vitro study of UA and oleanolic acid inhibiting cariogenic microorganisms as well as biofilm. Oral Diseases. 19: $494-500$. 